Role of agricultural engineering in environmental and sustainable development

for the valley and delta areas: 1343 - 1364

\title{
PERFORMANCE OF STRAW BALE WALLS AS A NATURAL BUILDING MATERIAL
}

\author{
Ashour, T.
}

\section{ABSTRACT}

This paper aimed to evaluate a straw bale house. An extensive test program was carried out. The experimental work includes compression tests, moisture content, compensation test and pH. The in-situ work includes temperature and relative humidity inside the straw bale wall. The stress-strain behavior of straw bales is investigated including nonlinearity and anisotropy. The deformation modulus and the resilient behavior are studied considering time dependence.

The moisture content of straw bale was about 11\%, while pH value inside the bale was about 7.29. Moreover, the temperature and the relative humidity between the interior (inside straw bale) and the exterior are studied for several straw bale thicknesses.

Keywords: Straw bale house, moisture content, pH, compression test, temperature, relative humidity

\section{INTRODUCTION}

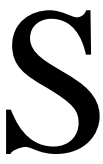

traw is a natural product, grown by photosynthesis during a half or one-year period, fueled by the sun. Straw is currently produced in surplus to requirements, so it is cheap and easily accessible in most countries. It is the final product of growing crops; so using it for building purposes present a sustainable and ecological way of recycling. The use of straw bales as construction material has many advantages (Bainbridge, 2005). Buildings with straw bales are energy-efficient, durable, attractive and even fire-resistant. According to Desborough and Samant (2009), the public would generally accept straw dwellings, especially when supported by wide dissemination of information about the material properties of straw and the construction possibilities. Additionally, built environment professionals find straw to be an excellent construction material and recognize that some of its limitations can easily be overcome. Earlier studies (Apte et al., 2003) showed that a compacted straw bale with a render layer of about $4 \mathrm{~cm}$ on all sides 
survived an externally imposed heat flux of $29 \mathrm{~kW} / \mathrm{m}^{2}$ for 10 minutes without severe cracking of the render or ignition of the straw within the bale. A straw bale without render readily ignited when subjected to the same heat flux. Clearly, the render contributes to the fire safety of straw bale construction by providing an insulating barrier between the heat source and the straw and also providing a barrier to oxygen transfer from the atmosphere into the straw. Straw bales have also been used to provide retrofit insulation for existing homes. The bales are much cheaper that adobe and have become common in high-end estate constructions.

On the other hand, faced with the worldwide shortage of forest resources, the construction industry is showing interest in the production of particleboard from agricultural residues (Sampathrajan et al., 1992). Wheat straw contains a large amount of fiber with the potential to replace wood for particleboard fabrication. Particleboard with a density range from 0.59 to $0.8 \mathrm{~g} / \mathrm{cm}^{3}$ is designated as medium-density particleboard (ASTM, 1995). It has broad applications for both structural and nonstructural uses. Also barley straw is a significant raw material in cellulose production as an energy resource (Johnson, 1973; Wollenberg et al., 1998; Witka-Jezewska et al., 1999; Joergensen et al., 1997; Welch et al., 1990; and Pillinger et al., 1994). The reuse of co-product straw in this manner is considered an environmentally friendly material, which helps to reduce heat in the house during summer, and keeps warmth during winter. The high silica content in the straw makes it resistant to decay, and its long fiber characteristic is good for building houses (Bruce, 2006). Modern buildings have tremendous impact on the environment in their life cycle. It results in different problems and has significant influence on climate change because of the energy use for production, building, maintenance and demolition (UNEPSBCI, 2009 and Petrossian, 2000). Some studies on straw bales have been carried out in the past. Ashour and Johansson, 2003 reported that strength of bale in vertical orientation was higher than those in the horizontal orientation and the deformation modulus decreased gradually with increasing load. The deformation modulus of vertically oriented bales was found to be higher than those of the horizontal oriented bales. Some investigations on earth plaster in straw bale buildings have been carried out in the past. The 
influence of natural reinforcement fibres on the erosion properties of earth plaster materials was studied by Ashour and Wu (2010). The fiber content and fiber type are found to have remarkable effect on the erosion resistance of the plasters. The excellent property of straw bales for acoustic insulation was shown in Deverell et al., 2009. However, most experimental work in the literature was carried out on straw bales in laboratory.

There are numerous publications on straw bale construction in literature. However, most publications deal with either laboratory testing or construction practice. A combination of housing project with extensive testing program is rarely found. Our paper presents an attempt to combine a housing project with straw bales with an extensive testing program. The straw bale house is located in Bavaria, Germany. The measurements include the following points: (1) The in-situ measurements include the behavior of temperature and relative humidity inside the straw bale wall under natural condition. (2) The laboratory measurements include bales dimensions, bale weight, compression test, compensation test, moisture content and $\mathrm{pH}$.

\section{Description of building}

Straw bales can be used either as load bearing structure or as infill wall. For the infill wall system, there are different techniques such as post and beam structures and frame (truss) structures with straw infill. The latter is widely used in construction practice. The loads are carried by the frame structures and the insulation is provided by the straw bales. The building under study is constructed with wood frames and straw infill.

In addition to the mechanical behavior of straw bales, it is very important to evaluate temperature and relative humidity inside the wall under natural conditions. A straw bale house in Germany was chosen for our investigations. The orientation of the straw bales inside the wall was horizontal. The house consisted of two floors as shown in Fig. 1. The wall thickness is about $50 \mathrm{~cm}$. The wall consists of calcium stucco as outside plaster $(1 \mathrm{~cm})$, outside plaster $(2 \mathrm{~cm})$, straw bale wall $(45 \mathrm{~cm})$ and inside plaster $(2 \mathrm{~cm})$. 


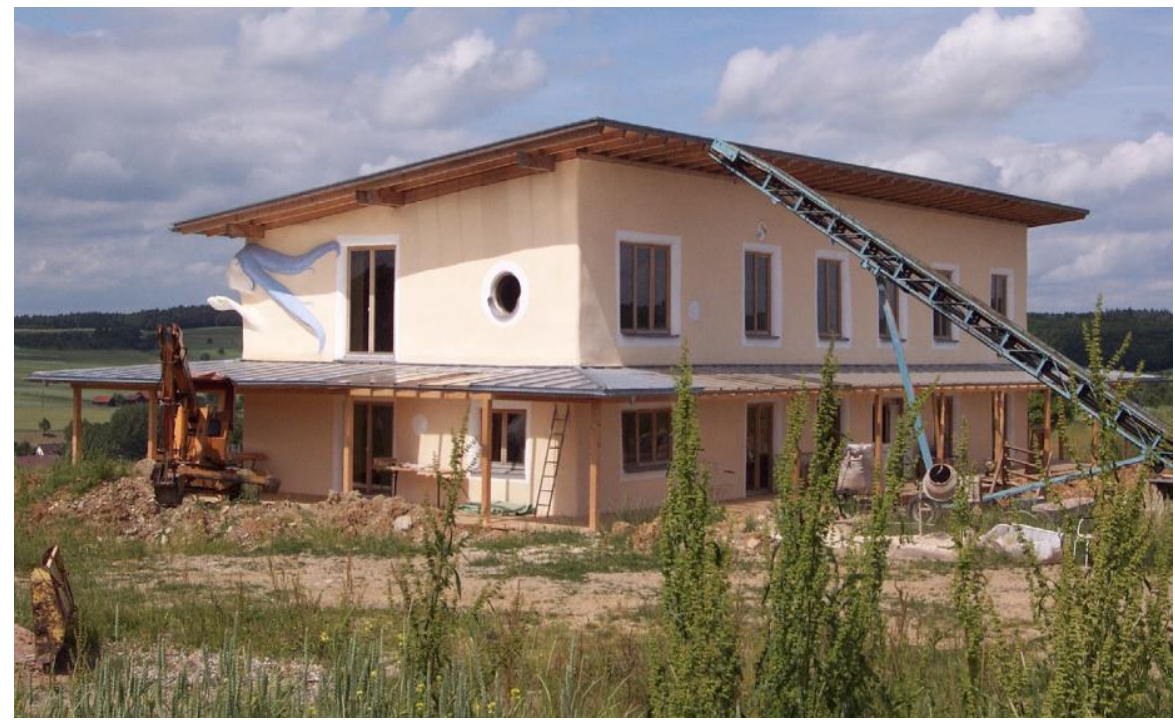

Fig.1. House for case study

The house includes different rooms such as bathroom, bedroom, living room, kitchen and others as shown in Fig.2.

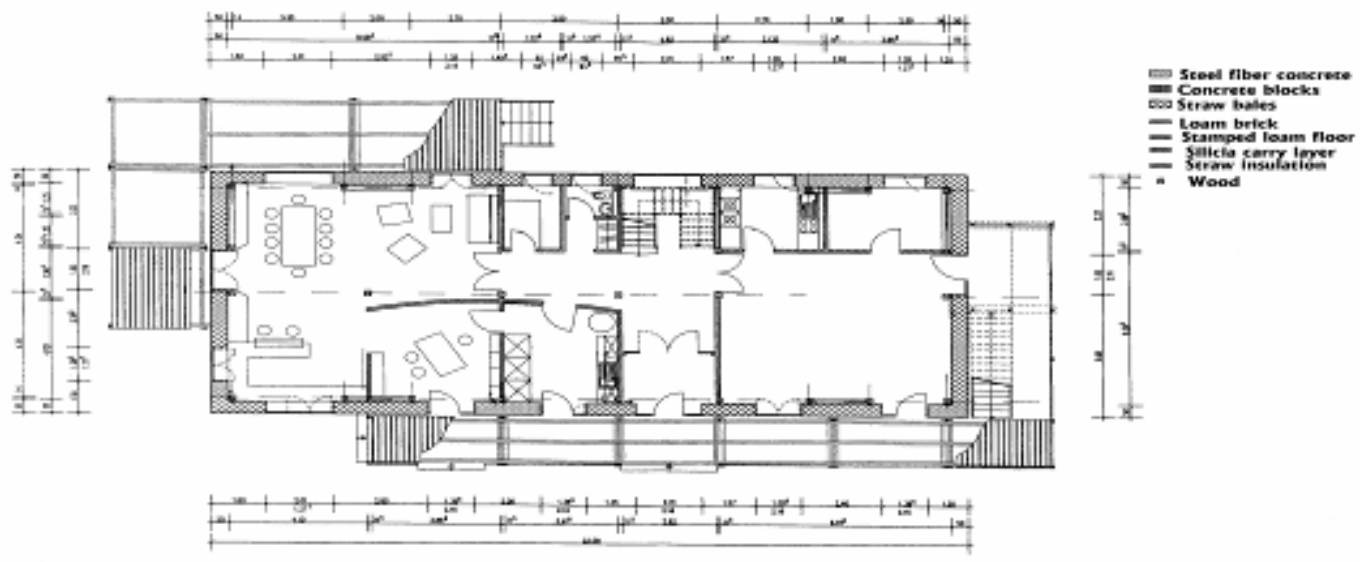

Fig.2. Plan view for the ground floor of the house. 


\section{Experimental programs}

\subsection{In-situ testing}

In-situ measurements are important to evaluate the performance of straw walls under natural conditions. The in-situ testing included the temperature and relative humidity inside the straw bale walls. The sensors for measuring the thermal and humidity behavior were installed at different locations in the wall. The commercial temperature and relative humidity sensors of the type of Negative Temperature Coefficient (NTC) were used for this investigation. The capacitive humidity sensors contain a glass substrate with a humidity-sensitive polymer layer between two metal electrodes. The measuring signal is proportional to the relative humidity and is independent of the atmospheric pressure. The probe pipe is made of aluminum with a diameter of $12 \mathrm{~mm}$. The device covers a wide measurement range, from $5 \%$ to $98 \%$ for relative humidity and from -20 to $+80{ }^{\circ} \mathrm{C}$ for temperature. Plastering is very important for the durability of straw bale constructions. The wall consisted of three layers such as outside plaster, straw wall and inside plaster. So the sensors should be covering all positions. The temperature sensors were installed on the plaster surface and inside the wall. The sensors were placed in the different positions such as outside temperature, outside plaster surface, between outside plaster and straw wall, $10 \mathrm{~cm}$ from outside, $20 \mathrm{~cm}$ from outside, between straw wall and inside plaster and inside plaster surface as shown in Fig. 3.

The temperature and relative humidity properties were measured in the ground floor and the sensors locations were depend the wall layers. The sensors position for the ground floor was at south east wall and $1.4 \mathrm{~m}$ above the floor.

\subsection{Laboratory measurements}

The in-situ tests were supplemented by extensive laboratory tests including bale densities, moisture content, $\mathrm{pH}$ and mechanical properties under compressive load.

\subsubsection{Bale dimensions and weight}

Linear dimensions of the bales, i.e. length, width, and height were measured. The bales were weighed to obtain the bale density 


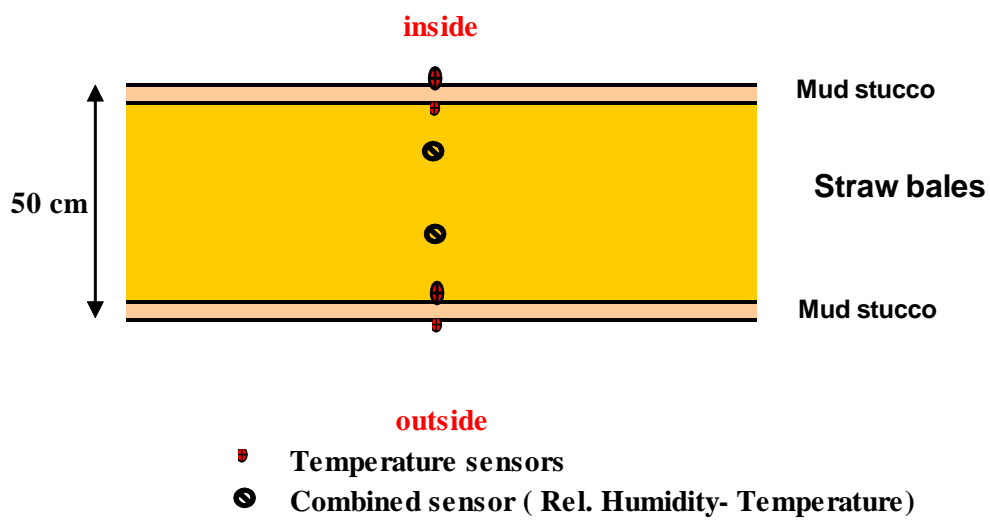

Fig.3. Sensors positions inside the wall

\subsubsection{Moisture content}

The moisture content of straw bales was measured according to ASHRAE, 1997. The bales were put in an oven at $105{ }^{\circ} \mathrm{C}$ until the weight of the samples became constant. The samples were weighed before and after drying. The moisture content was then calculated according to $\mathrm{MC}=\left(\left(\mathrm{W}_{\mathrm{m}}-\mathrm{W}_{\mathrm{d}}\right) / \mathrm{W}_{\mathrm{d}}\right) * 100$, where $\mathrm{MC}$ : Moisture content of the bale for dry weight $(\%) ; \mathrm{W}_{\mathrm{m}}$ : Moist weight $(\mathrm{kg})$ and $\mathrm{W}_{\mathrm{d}}$ : Dry weight $(\mathrm{kg})$.

\subsubsection{Measurement of $\mathrm{pH}$ values}

Straw is an organic building material. The environmental, physical and chemical properties of straw inside the bales are of importance for the durability of straw buildings. The environmental condition includes temperature, relative humidity, Oxygen and $\mathrm{pH}$. When the condition inside the bale is optimal for micro-organisms, the growth of these micro organisms will be enhanced. The growth of micro-organisms leads to straw deterioration and has negative effect on the durability of straw building. Beside temperature and humidity, the $\mathrm{pH}$ value, i.e. an acidity or alkalinity environment, is important for the growth of microorganisms. A total of 16 samples were used to measure the $\mathrm{pH}$ values, with 4 replicates for straw from the house under studying. To make an extraction for measuring the $\mathrm{pH}$, the straw was dried at $105^{\circ} \mathrm{C}$ for 24 hours and 5 grams from dried straw were mixed with 45 gram of distilled water with the ratio of 1: 9 between straw and water. The straw was mixed with water for 30 minutes, and then the $\mathrm{pH}$ measuring was started. The $\mathrm{pH}$ value was measured every 60 minutes over a period of 5 hours (Fig.4). 


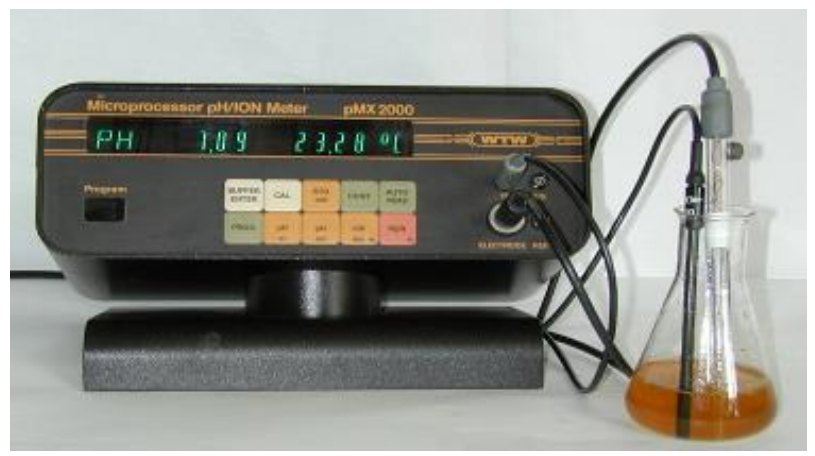

Fig.4. Instrument for measuring the $\mathrm{pH}$ value of Straw

\subsubsection{Thermal stability of bales}

The tests were carried out to measure the temperature and relative humidity in straw bales. The measurements were made when equilibrium was reached between the straw bale and the ambience. A compensation for temperature and relative humidity was carried out according to DIN (1991). A total of 10 bales were used for this test. A dual sensor was placed in the centre of each bale. The tests were carried out in a climate chamber with $23{ }^{\circ} \mathrm{C}$ and $78 \%$ relative humidity (Fig. 5). The test was performed under high relative humidity to study the temperature and humidity transfer from environment to straw bale.

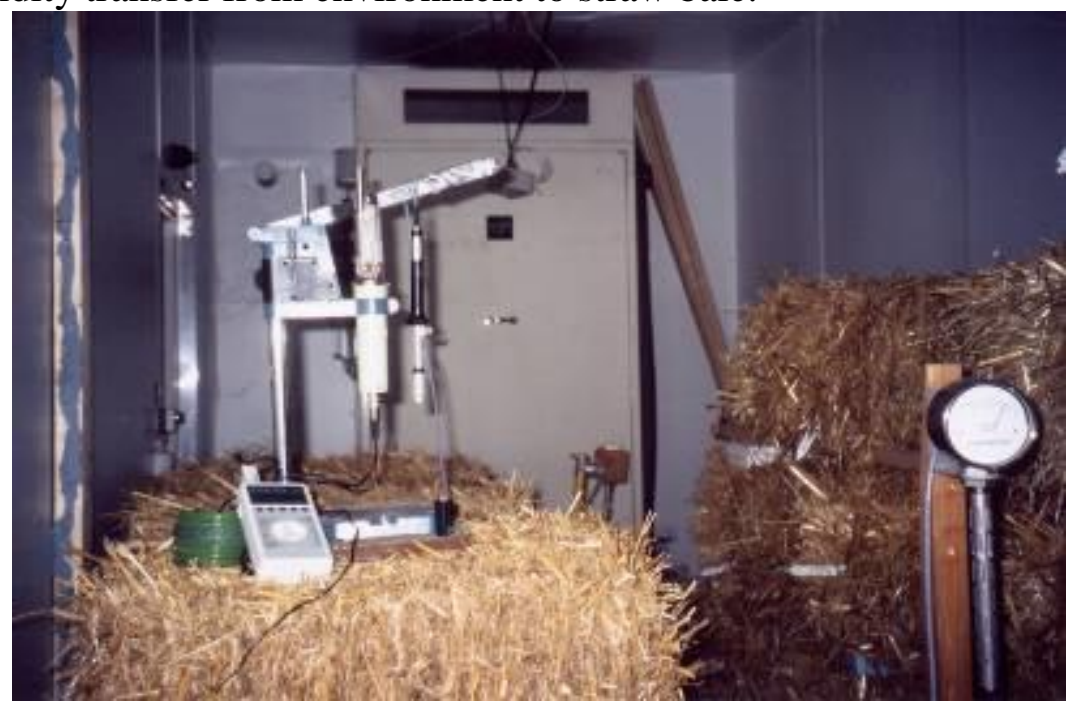

Fig.5. Bales inside the climate chamber under compensation test condition 
The test was terminated when the temperature and relative humidity inside the bales became equal to the temperature and relative humidity in the climate chamber.

\subsubsection{Mechanical properties}

The mechanical properties were investigated by compression tests according to DIN (1984). The tests were carried out on a total of 10 straw bales from the building. The straw bales were tested in horizontal and vertical orientations. For the case of horizontal orientation the dimension of the bales was about $61 \mathrm{~cm}$ long $43 \mathrm{~cm}$ wide and $36 \mathrm{~cm}$ high. For the case of vertical orientation the dimension was about $61 \mathrm{~cm}$ long $36 \mathrm{~cm}$ wide and $43 \mathrm{~cm}$ high.

A vertical load of about $2 \mathrm{kN}$ was first applied to the bale. Afterwards, the vertical load was increased in increment by $1 \mathrm{kN}$ to reach the maximum load of about $10 \mathrm{kN}$. The loading piston was then stopped after each increment and the bale dimensions were measured as shown in Fig.6. At the end of each test the bales were dried to measure the moisture content of the bales. The stress, horizontal strain, vertical strain and the deformation modulus were evaluated (according to Kozachenko et al., 1998).

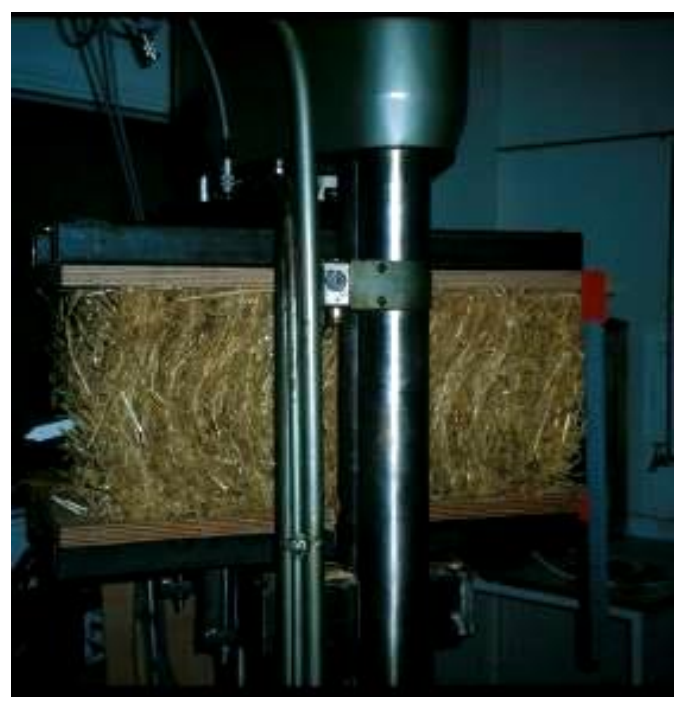

Fig.6. Straw bale in compression test 


\section{RESULTS AND DISCUSSION}

\subsection{Bales dimensions, density, moisture content and $\mathrm{pH}$ value}

The straw bales were about $60 \mathrm{~cm}$ long, $46 \mathrm{~cm}$ wide and $34 \mathrm{~cm}$ with an average volume of about $0.09 \mathrm{~m}^{3}$. The average of bales density was 102.6 $\mathrm{kg} / \mathrm{m}^{3}$. The moisture of bales is responsible of its deterioration as a result of the microbial activity. The average moisture content was about $11 \%$. The moisture content of about $15 \%$ is thought to be safe for the straw bale according to Bainbridge, 1986.

The average of $\mathrm{pH}$ value of straw inside the bales was about 7.29. This means that the condition inside the bales is alkaline. This $\mathrm{pH}$ value is typical for straw material. Beside the moisture content, the $\mathrm{pH}$ values inside the bales are important for the microbial activity. Fungi and microorganisms may activate inside the bales and cause deterioration of the bales and decrease the building life. Further research in this area is needed in the future.

\subsection{Mechanical properties}

\section{a. Stress and load}

Fig.7 shows the relationship between the applied load and the stress for horizontally and vertically oriented straw bales. The cross-sectional area was about $0.204 \mathrm{~m}^{2}$ in vertical direction and $0.276 \mathrm{~m}^{2}$ in horizontal direction. The applied load started with $2 \mathrm{kN}$ and increased in increments to reach $10 \mathrm{kN}$ at the end of test. The figure shows that the stress increases with increasing load for both vertically and horizontally oriented bales. At the beginning ( $2 \mathrm{kN}$ load), the average stress was about $9.95 \mathrm{kN} / \mathrm{m}^{2}$ for the vertical orientation. This was higher than that of the horizontally oriented bales of $7.6 \mathrm{kN} / \mathrm{m}^{2}$. While at $10 \mathrm{kN}$ load, the same trend can be observed, the average stress was about $45.2 \mathrm{kN} / \mathrm{m}^{2}$ at vertical orientation while it was $32.9 \mathrm{kN} / \mathrm{m}^{2}$ for the horizontal orientation bales. The difference in stresses for the vertical and horizontal orientations was due to the different cross-sectional areas.

The overall average stress $\left(28.4 \pm 12.3 \mathrm{kN} / \mathrm{m}^{2}\right)$ for vertical orientation was higher than that of horizontal orientations $\left(21.1 \pm 8.7 \mathrm{kN} / \mathrm{m}^{2}\right)$. This may be due to the fact that the bales of horizontal orientation have larger cross-section area compared to that of bales of vertical orientation. Also, the direction of the straw stems in the vertical orientation is different from that in the horizontal orientation. 
$\rightarrow-$ horizontal $\quad-*-$ vertical

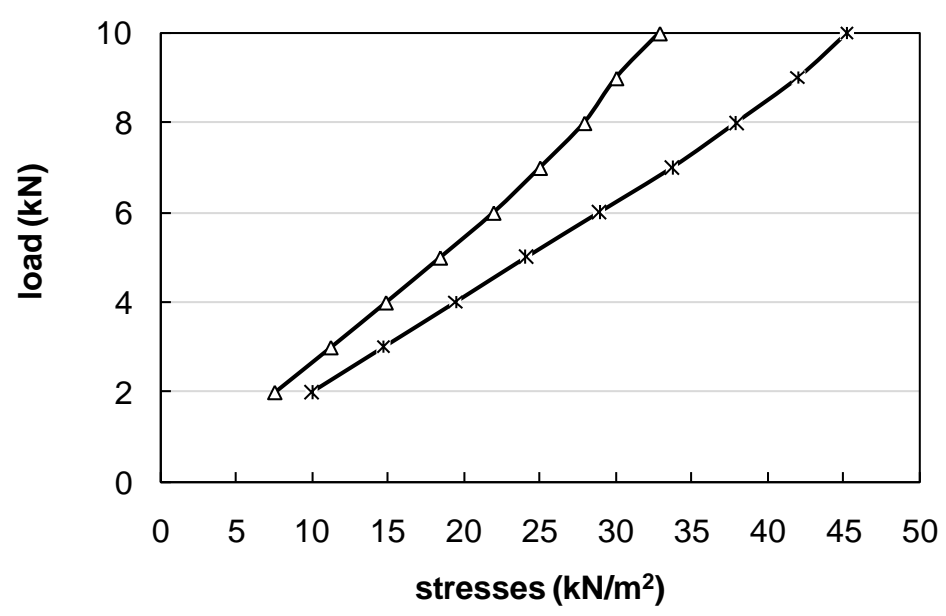

Fig.7. Stress in straw bales

\section{b. Vertical strain}

The strain is defined as the displacement of the bale divided by the original height of the bale. The vertical and horizontal deflections were measured for two different orientations (vertical and horizontal). Fig.8 shows the relation between load and vertical strain for vertically and horizontally oriented straw bales. For small load up to about $2 \mathrm{kN}$ there is only very small strain in the bales.

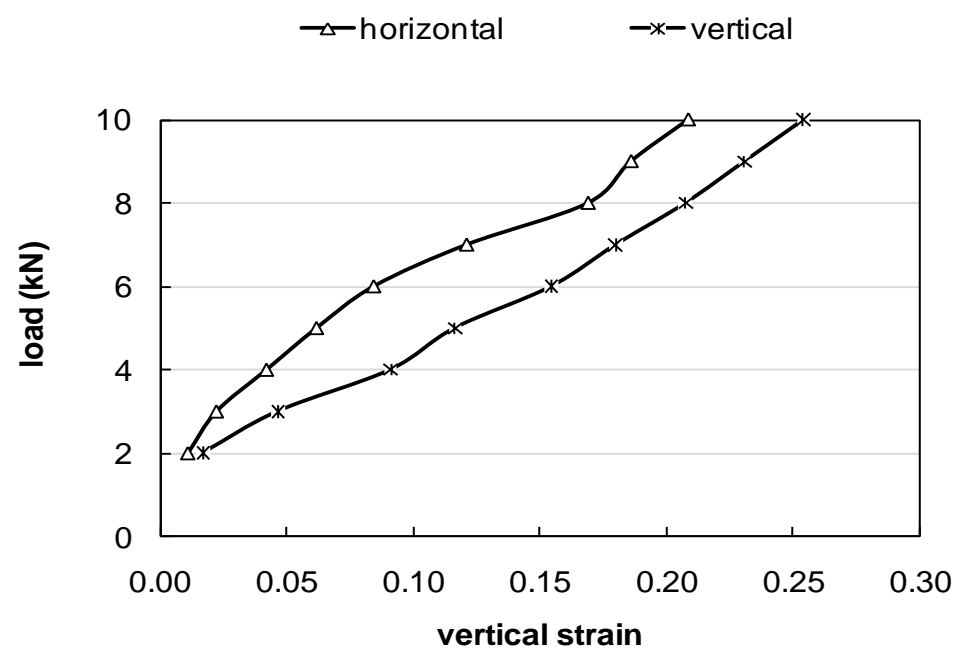

Fig.8. Vertical strain of straw bales under compression test 
For vertically orientated bales, the maximum strain was about 0.25 and the minimum strain was about 0.017 . It is clearly that the resistance to deflection increases with applied load. For horizontally oriented bales, the vertical strain ranged from 0.011 to 0.208 . From the results we can see that the vertical strain ranged from $0.017-0.254$ at loads from $2-10$ $\mathrm{kN}$ for the vertically oriented bales while it ranged from $0.011-0.208$ for the horizontally oriented straw bales.

The vertical strain values increased with increasing load for both vertical and horizontal orientations. It is also clear that the vertical strain values for vertical orientation were higher than those for horizontal orientation.

\section{c. Horizontal strain}

Fig.9 shows the relationship between the horizontal strain and load of vertically and horizontally oriented straw bales. By increasing the load, horizontal strain was observed where it reached to a minimum of 0.10 at $10 \mathrm{kN}$ for vertical oriented bales and 0.15 for horizontal oriented bales.

\section{$\rightarrow-$ horizontal $\quad \rightarrow *-$ vertical}

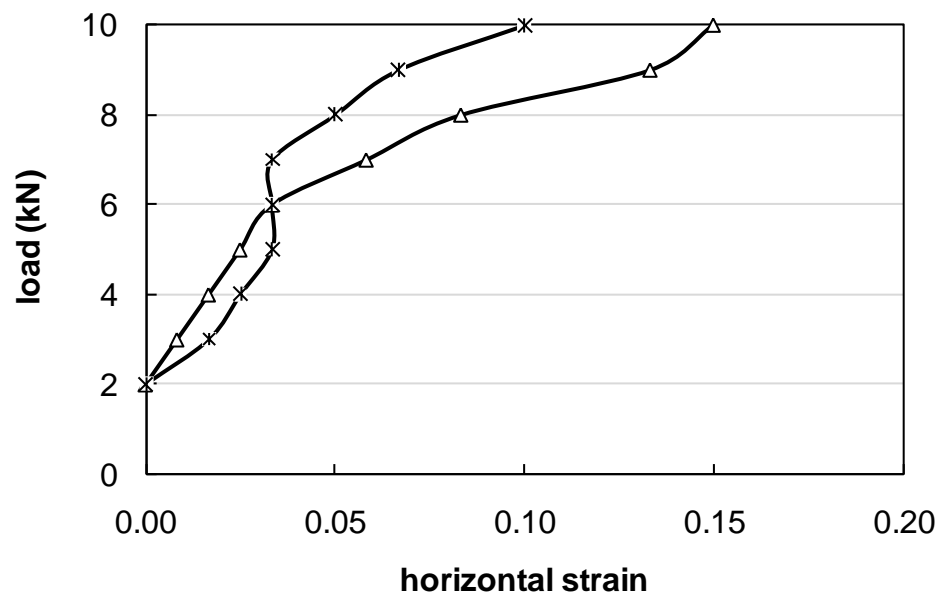

Fig.9. Horizontal strain for straw bales under compression test

The average horizontal strain for the horizontal oriented bales is larger than that of vertical oriented bales. The average horizontal strain ranged from $0.04 \pm 0.03$ for the vertical oriented bales which it ranged from 0.06 \pm 0.05 for the horizontally oriented bales. 
It is worthily to be noticed from Fig. 8 and Fig.9 that, the vertical strain is higher than the horizontal strain for both vertically and horizontally oriented bales.

\section{d. Deformation modulus}

Fig.10 shows the relationship between the deformation modulus and the applied load for the straw bales at different orientations. The deformation modulus is calculated as the ratio between stress increment and strain increment. It can be seen that the deformation modulus decreases with increasing load for both bale orientations. The stress-strain behaviour of straw bales is nonlinear. Under increasing load the deformation modulus decreases to reach a value of about $200 \mathrm{kPa}$ for both bale orientations.

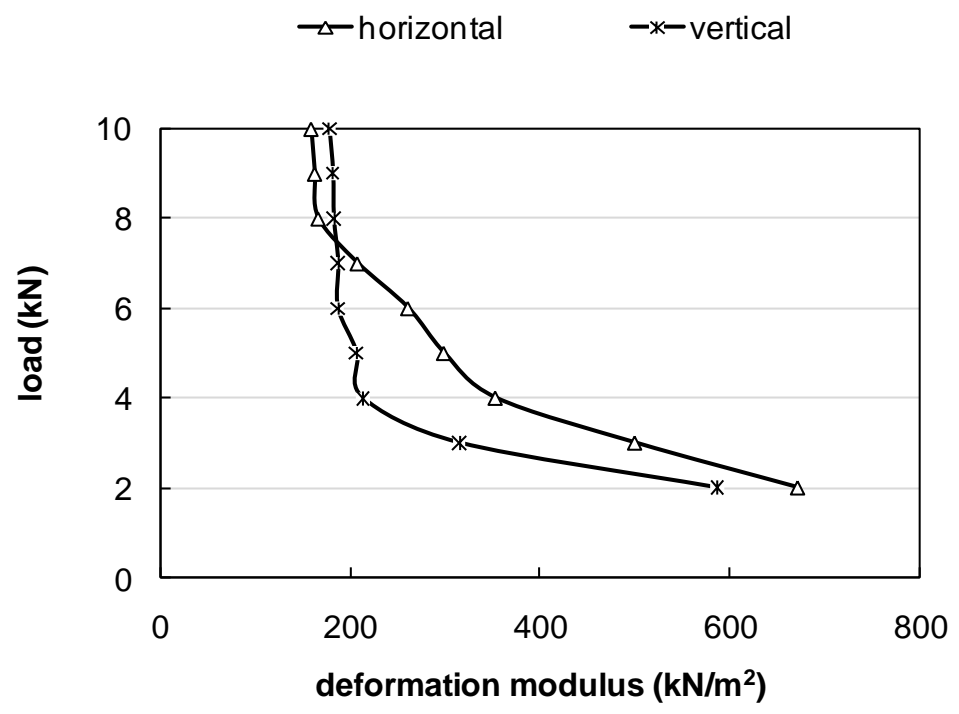

Fig.10. Deformation modulus during compression test.

It can be seen that the deformation modulus decreased gradually with increasing load. At the load of about $4 \mathrm{kN}$ the deformation modulus reached $213 \mathrm{kPa}$ and remained unchanged for the vertically oriented bales. While for the horizontally oriented bale the deformation modulus reached a constant modulus of about $165 \mathrm{kPa}$ at the load of about $8 \mathrm{kN}$. This decrease of deformation modulus was attributed to the initial compression of the voids among the straw fibres. The constant modulus at higher load represented the resistance of well compressed straw bales. The reduction of the deformation modulus does not mean that the 
resistance against deflection decreases. The resistance still increases nonlinearly. These experimental results agree well with those reported in Ashour 2003; Bou-Ali 1993 and Watts et al., 1995).

\section{e. Stress-strain relationship}

Fig.11 shows the stress-strain curves for vertically and horizontally orientated straw bales. The nonlinear behavior can be clearly observed. It is worth to mention that all bales showed highly resilient behavior, i.e. the deformation was recovered after the load was removed. However, the recovery of deformation after load removal took several minutes. The time required for a complete recovery of deformation varied between 10 and 13 minutes for both vertically and horizontally oriented bales.

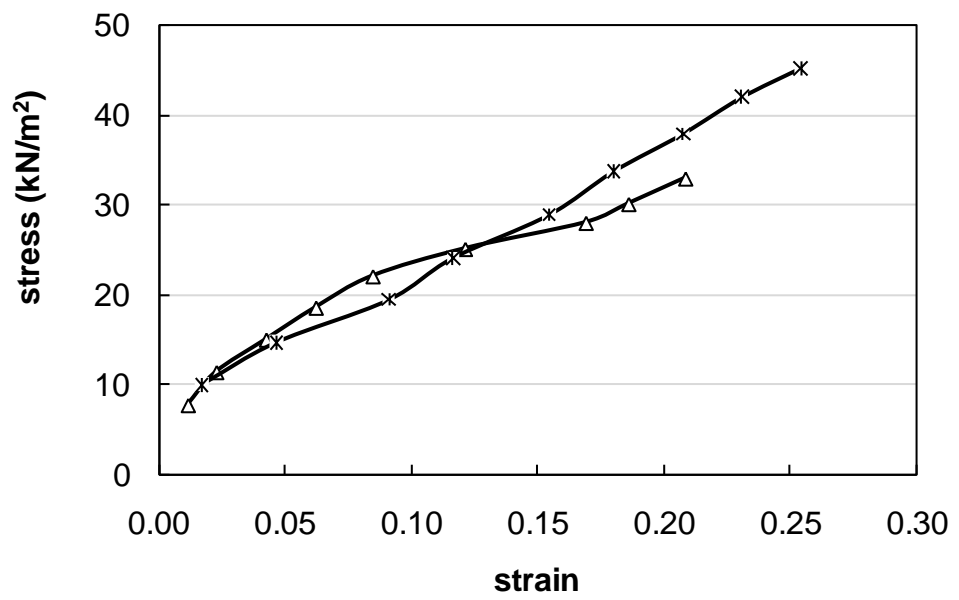

Fig.11. Stress-Strain relationship for straw bales during compression test

\subsection{Thermal stability of bales}

The thermal stability of bales was investigated by placing the bales in a climate chamber with controlled atmosphere at $23^{\circ} \mathrm{C}$ and $78 \%$ relative humidity. Ten straw bales were used for testing. The sensors were placed in the center of the bales to record temperature and relative humidity. The measurements were continued until a stability condition was achieved. Readings of the temperature and relative humidity were taken every 5 minutes. In general some 450 hours were needed. 


\subsubsection{Temperature measurements}

Fig. 12 shows the temperature of straw bales from the house of case study with time together with the ambient temperature of about $23{ }^{\circ} \mathrm{C}$. The tests were carried out on straw bales with an average density of about $102.6 \mathrm{~kg} / \mathrm{m}^{3}$. Starting from an initial temperature of about $23.1^{\circ} \mathrm{C}$, the temperature in bale showed an initial sharp increase to about $23.6{ }^{\circ} \mathrm{C}$ followed by a gradual decrease to about $23.21{ }^{\circ} \mathrm{C}$ at $450 \mathrm{hr}$. The difference between the surrounding temperature and bale temperature decreased with time. However a small difference between the ambient temperature and the temperature in bale remained after 450 hours. This is ascribed to the insulation function of the straw material. A closer examination of the data showed that temperature decreased with time according to an exponential equation with the correlation of about $80.05 \%$.

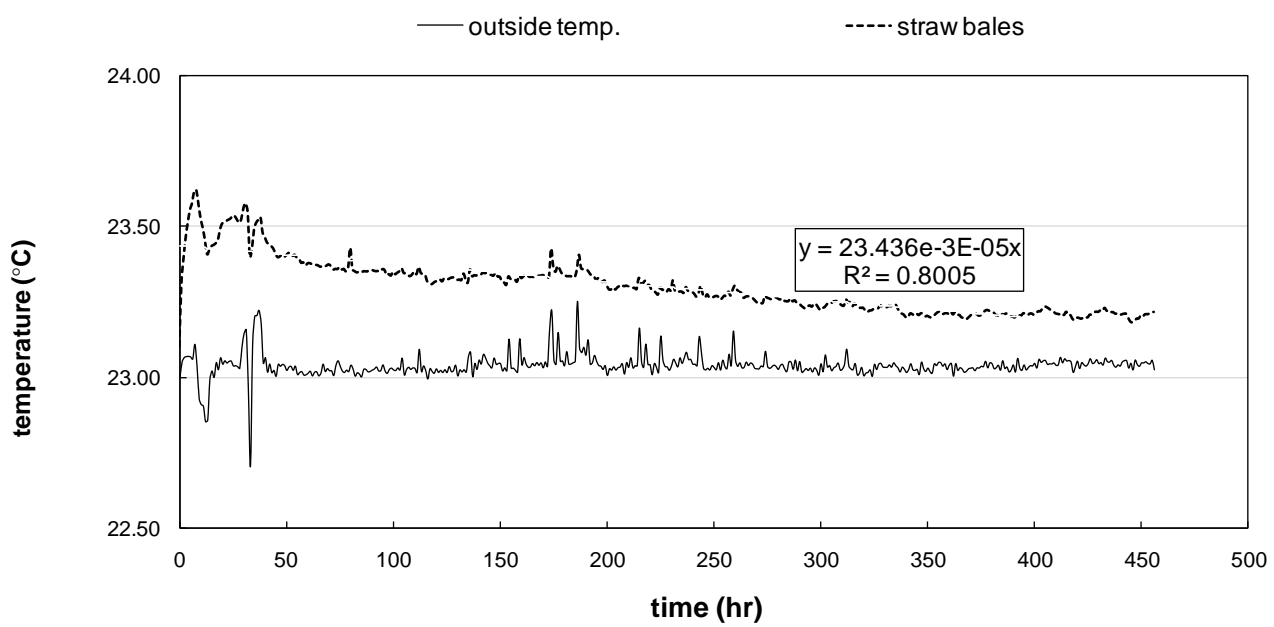

Fig.12. Temperature evolution of straw bale

\subsubsection{Relative humidity}

Fig.13 shows the relative humidity of straw bales from the straw house under study with time together with the surrounding relative humidity of about $78 \%$. The test was started with an initial relative humidity of about $68.65 \%$ in bale. After an initial steep increase the relative humidity increased gradually with time to reach $76.4 \%$ after 450 hours. The difference between the surrounding relative humidity and the relative 
humidity in bale decreased with time. At 400 hours this difference was about $3.44 \%$. At the end of test (after 450 hour), this difference was only about $2.55 \%$.

It is interesting to observe that the temperature and relative humidity in bale differed from the outside condition even after 450 hours. Our results showed that relative humidity increased with time according to an exponential equation with the correlation of $94.04 \%$. The results showed the excellent insulation function of straw materials against the outside relative humidity. This could be owed to the low moisture content of straw. Therefore, it took very long time to reach equilibrium with the outside conditions.

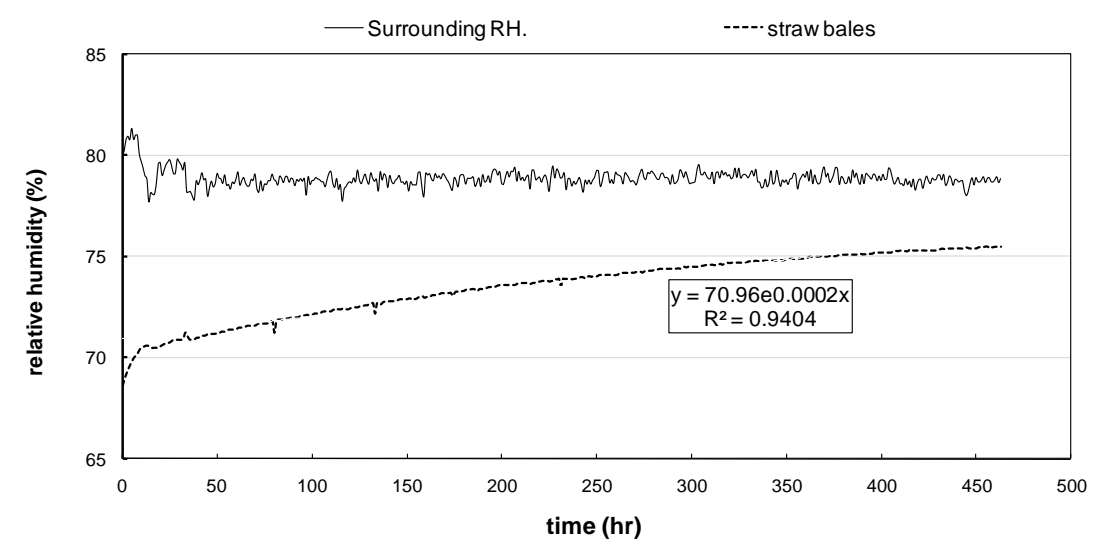

Fig.13. Evolution of relative humidity inside the bale

\subsection{Temperature and relative humidity behavior inside the walls 4.4.1Temperature measurement}

The temperature was recorded at different locations, at outside temperature, on outside plaster surface, in straw wall at $10 \mathrm{~cm}$ from outside, $20 \mathrm{~cm}$ from outside and on the inside plaster surface. Fig.14 shows the temperature evolution inside the wall at different locations of the straw bale wall of the ground floor. It is shown that the temperature gradient increased from outside (low temperature) towards the inner side of wall. Moreover, the extreme outside temperature peaks were smoothed out by the straw wall. 
Table 2 shows the average temperature at different locations and times inside the straw bale wall. At the beginning, the average temperatures were $12.7,12.1,12.5,13.73,13.43,13.5$ and $13.7{ }^{\circ} \mathrm{C}$ for outside temperature, outside plaster surface, between outside plaster and straw bale, $10 \mathrm{~cm}$ in straw, $20 \mathrm{~cm}$, in straw, between straw and inside plaster and inside plaster surface, respectively.

After 24 hours, the temperature increased towards the wall interior, where the temperature difference between the outside temperature and the different location are $0.04,0.19,2.11,2.04,0.62$ and $0.26{ }^{\circ} \mathrm{C}$ for outside temperature, outside plaster surface, between outside plaster and straw bale, $10 \mathrm{~cm}$ in straw, $20 \mathrm{~cm}$, in straw, between straw and inside plaster and inside plaster surface, respectively.

After 96 hours, the temperature percentages between the ambient temperature and the wall interior were 12.18, 16, 29.1, 29.7, 11.25 and $19.9 \%$ for outside plaster surface, between outside plaster and straw bale, $10 \mathrm{~cm}$ in straw, $20 \mathrm{~cm}$, in straw, between straw and inside plaster and inside plaster surface, respectively.

It is interesting to observe that the percentage inside straw is higher than the outside plaster. While it was $29,1 \%$ and $29.7 \%$ for 10 and $20 \mathrm{~cm}$ inside straw. This may be due to the fact that the outside plaster is influenced by outside conditions and its lower thermal insulation in comparison with straw.

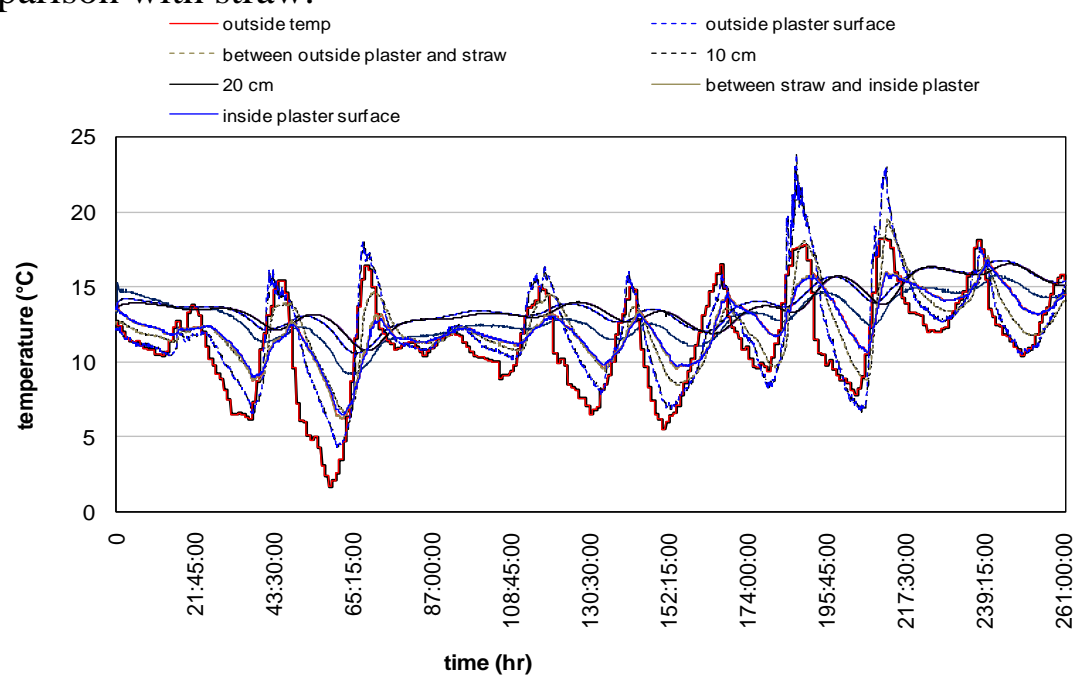

Fig.14. Temperature evolution across straw wall of the ground floor. 
At the end of test (261 hours), the temperature percentages between the outside temperature and the other side of the wall bales were 5.83, 6.59, 20.86, 19.68, 9.46 and $111.99 \%$ for outside plaster surface, between outside plaster and straw bale, $10 \mathrm{~cm}$ in straw, $20 \mathrm{~cm}$, in straw, between straw and inside plaster and inside plaster surface, respectively.

Table 1 and Fig.14 showed also that the temperature inside the straw wall was stable despite the large difference of outside temperature between day and night. The results also revealed that straw wall smoothed out the extreme temperature peaks outside and provide better living conditions.

Table 1. Average temperature at different locations and time

\begin{tabular}{|c|c|c|c|c|c|c|c|}
\hline \multirow[b]{2}{*}{$\begin{array}{l}\text { time } \\
\text { (h) }\end{array}$} & \multirow[b]{2}{*}{$\begin{array}{c}\text { outside } \\
\text { temp. }\left({ }^{\circ} \mathrm{C}\right)\end{array}$} & \multicolumn{3}{|c|}{ between } & \multicolumn{3}{|c|}{ between } \\
\hline & & $\begin{array}{l}\text { Outside } \\
\text { plaster. } \\
\text { surface }\end{array}$ & $\begin{array}{c}\text { outside } \\
\text { plaster } \\
\text { and } \\
\text { straw }\end{array}$ & $\begin{array}{l}10 \\
\mathrm{~cm}\end{array}$ & $\begin{array}{l}20 \\
\mathrm{~cm}\end{array}$ & $\begin{array}{l}\text { straw } \\
\text { and } \\
\text { inside } \\
\text { plaster }\end{array}$ & $\begin{array}{l}\text { Inside } \\
\text { plaster } \\
\text { surface }\end{array}$ \\
\hline 0 & 12.70 & 12.10 & 12.50 & 13.73 & 13.43 & 13.50 & 13.70 \\
\hline 24 & 11.78 & 11.82 & 11.97 & 13.89 & 13.72 & 12.40 & 12.04 \\
\hline $24-96$ & 9.69 & 10.87 & 11.24 & 12.51 & 12.57 & 10.78 & 11.62 \\
\hline $96-261$ & 11.84 & 12.53 & 12.62 & 14.31 & 14.17 & 12.96 & 13.26 \\
\hline
\end{tabular}

\subsubsection{Relative humidity}

Relative humidity is a very important factor especially for straw bale buildings. Relative humidity values were recorded at different locations, i.e. outside house and inside the wall (at $10 \mathrm{~cm}$ and $20 \mathrm{~cm}$ from external surface). Fig. 15 shows the relative humidity evolution inside the wall at different locations. The average values are given in Table 2. At the beginning, the average relative humidity values were $78.77,71.76$ and $68.82 \%$ for outside relative humidity $10 \mathrm{~cm}$ in straw, and $20 \mathrm{~cm}$, in straw, respectively.

After 24 hours, the relative humidity difference between the outside relative humidity and the different location are 8.67 and $6.36 \%$ for 10 and $20 \mathrm{~cm}$, respectively.

After 96 hours, the relative humidity percentages between the surrounding relative humidity and the other side of the wall bales were 11.86 and $8.29 \%$ for 10 and $20 \mathrm{~cm}$, respectively.

After 261 hours, the relative humidity percentages between the outside relative humidity and the other side of the wall bales were 5.74 and 2.63 $\%$ for 10 and $20 \mathrm{~cm}$, respectively. 


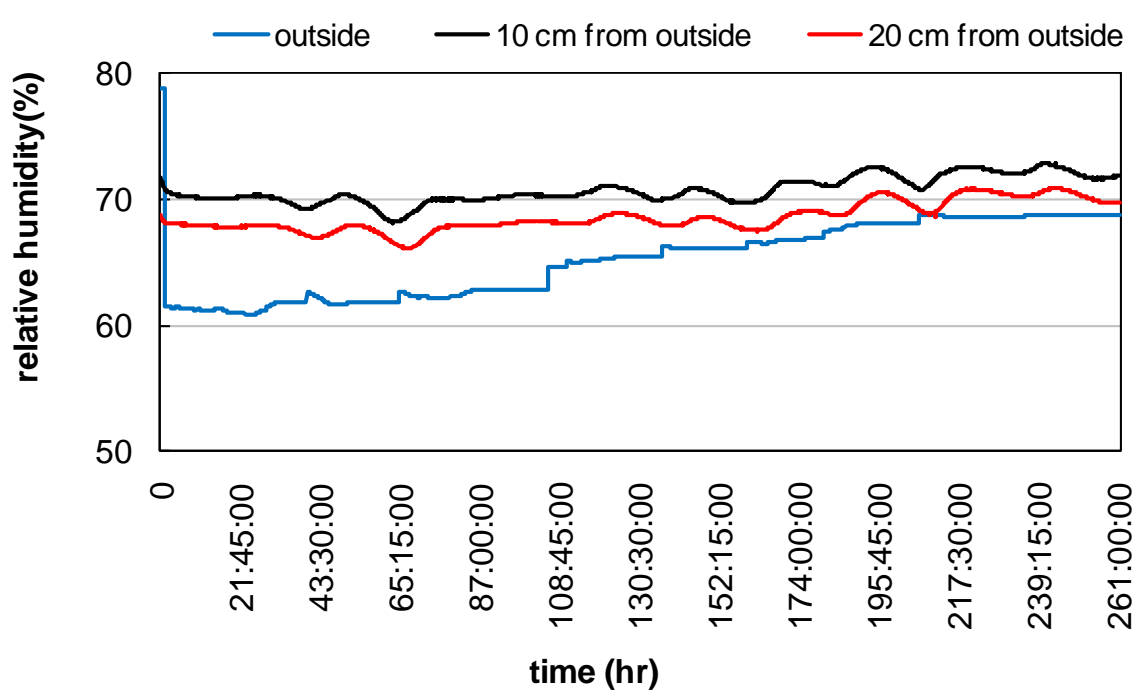

Fig.15. Relative humidity distribution inside the wall for the ground floor

Table 2. Average relative humidity at different locations and time.

\begin{tabular}{lccc}
\hline $\begin{array}{l}\text { time } \\
(\mathrm{h})\end{array}$ & $\begin{array}{c}\text { Outside relative humidity } \\
(\%)\end{array}$ & $\begin{array}{c}10 \mathrm{~cm} \text { from } \\
\text { outside }\end{array}$ & $\begin{array}{c}20 \mathrm{~cm} \text { from } \\
\text { outside }\end{array}$ \\
\hline \hline 0 & 78.77 & 71.76 & 68.82 \\
24 & 61.58 & 70.25 & 67.94 \\
$24-96$ & 62.33 & 69.72 & 67.50 \\
$96-261$ & 67.39 & 71.26 & 69.16 \\
\hline \hline
\end{tabular}

Table 2 and Fig. 15 show also that the relative humidity behavior inside the straw wall is stable although there are large variations outside between day and night. At the beginning of the test the relative humidity inside the straw bale wall was higher than those outside. This means that the moisture migration through the straw bale wall was very slowly.

\section{CONCLUSIONS}

There is only a small database in literature for straw buildings in the northern hemisphere. The present paper provides systematic measurements of several important variables in a house with straw bale walls in Germany. An extensive testing program was carried out. The straw bales showed nonlinear stress-strain behavior with pronounced nonlinearity at lower loading level. The bales showed apparent 
anisotropic behavior with the vertical strain for vertical orientation higher than those for horizontal orientation. Upon load removal the bales showed time dependent behavior with the time required for a complete recovery of deformation at about 10 to 13 minutes. The measurements of temperature and relative humidity showed that the straw walls had excellent properties to provide excellent living conditions. The extreme outside temperatures were smoothed out by the straw walls. Admittedly, the time of some measurements was still too short particularly the relative humidity in bale, which plays an important role in the long term behavior of straw walls. The moisture content of the straw bales was about $11 \%$, which was less than $15 \%$ (safe condition for straw bale buildings). The $\mathrm{pH}$ value inside the bale was about 7.29, which implied an alkaline environment. More in-situ measurements are needed to provide more confidence in the durability of straw bales in the northern hemisphere.

\section{Acknowledgement}

The author would like to thank Warmth Family in Bavaria, Germany for their support and help through this work.

\section{REFERENCES}

Apte VB, Paroz B and Bhargava A (2003). Fire safety testing and modeling of rendered straw bales for construction in bushfire prone areas. Proceedings of the $4^{\text {th }}$ International Seminar on Fire and explosion Hazards, University of Ulster, Northern Irland, September; 537-546.

Ashour T (2003). The use of renewable agricultural by-products as building materials. Ph.D thesis, Benha University, Egypt. (http://www.downloads.fasba.de/TahaAshour-2003-complete.pdf).

Ashour T, and Wu W (2010). The influence of natural reinforcement fibres on erosion properties of earth plaster materials for straw bale buildings. Journal of Building Appraisal, 5(4): 329-340.

ASHRAE. (1997). ASHRAE Handbook, Fundamentals. New York. American Society of Heating and Refrigerating air conditioning Engineers, Inc. 
ASTM D1554-86 (1995). American Society for Testing and Materials. Standard Terminology Relating to Wood-based Fiber and Particle Panel Materials, West Conshohocken, PA; pp. 225-/227.

Bainbridge DA (1986). High performance low cost buildings of straw. Agricultural, Ecosystems and Environment; 16: 281-284.

Bainbridge DA (2005). Houses of straw: Building solid and environmentally conscious. foundations. Engineering and Technology for Sustainable World; 12(4):7-8.

Bou-Ali G (1993). Straw bale wall systems. Civil Engineering, Thesis, university of Arizona.

Bruce K (2006). Design of Straw Bale Buildings. Green Building Press, San Rafael, CA.

Desborough $N$ and Samant $\mathbf{S}$ (2009). Is straw a viable building material for housing in the United Kingdom?. Journal of Sustainability, 2(6): 368-374.

Deverell R, Goodhew S, Griffiths R, and de Wilde P (2009). The noise insulation properties of non-food-crop walling for schools and colleges: A case study. Journal of Building Appraisal, 5(1): 29-40.

DIN, 52620 (1991). Bestimmung des Bezugsfeuchtegehalts von Baustoffen.

Joergensen R G, Figge RM and Kupsch LZ (1997). Pflanzenernaehr Bodenkd; 160 (1): 21.

Johnson RF (1973). Environ. Sci. Technol; 7 (5): 439.

Kozachenko A, Bart Yu and Rubtsov A (1998). Strength of materials. Mir Publishers, Moscow.

Petrossian B and Johansson E (2000). Construction and EnvironmentImproving Energy Efficiency. http://www.hdm.lth.se/bi/report/2000-02/00no2.pdf

Pillinger JM, Cooper JA and Ridge IJ (1994). Chem. Ecol; 20 (7): 1557. 
Sampathrajan A, Vijayaraghavan NC and Swaminathan KR (1992). Mechanical and thermal properties of particleboards made from farm residues. Bioresource Technology; 40: 249-251.

UNEPSBCI (2009). Buildings Can Play a Key Role in Combating Climate Change. United Nation of Environment Program for sustainable Buildings \& Climate Initiative; http://www.unep.org/sbci/pdfs/SBCI-BCCSummary.pdf

Watts KC, Wilkie KI, Tompson K and Corson J (1995). Thermal and mechanical properties of straw bales as they relate to a straw house. Canadian Society of Agricultural Engineering, Paper no. 1995-209.

Welch IM, Barret PRF, Gibson MT and Ridge J (1990). J. Appl. Phytol; 2, 231.

Witka-Jezewska E, Hupka J and Pieniazek P (1999). Proceedings of the US United Engineering Foundation Conference and 2nd International Conference Analysis and Utilization of Oily Wastes (AUZO'99), Jurata, Poland, August 29-30; pp. 63-67.

Wollenberg R, Naundorf W, Abraham J, Edel J, Trommer D and Mieth A (1998). Offen. DE 1998; 19628751 A1.

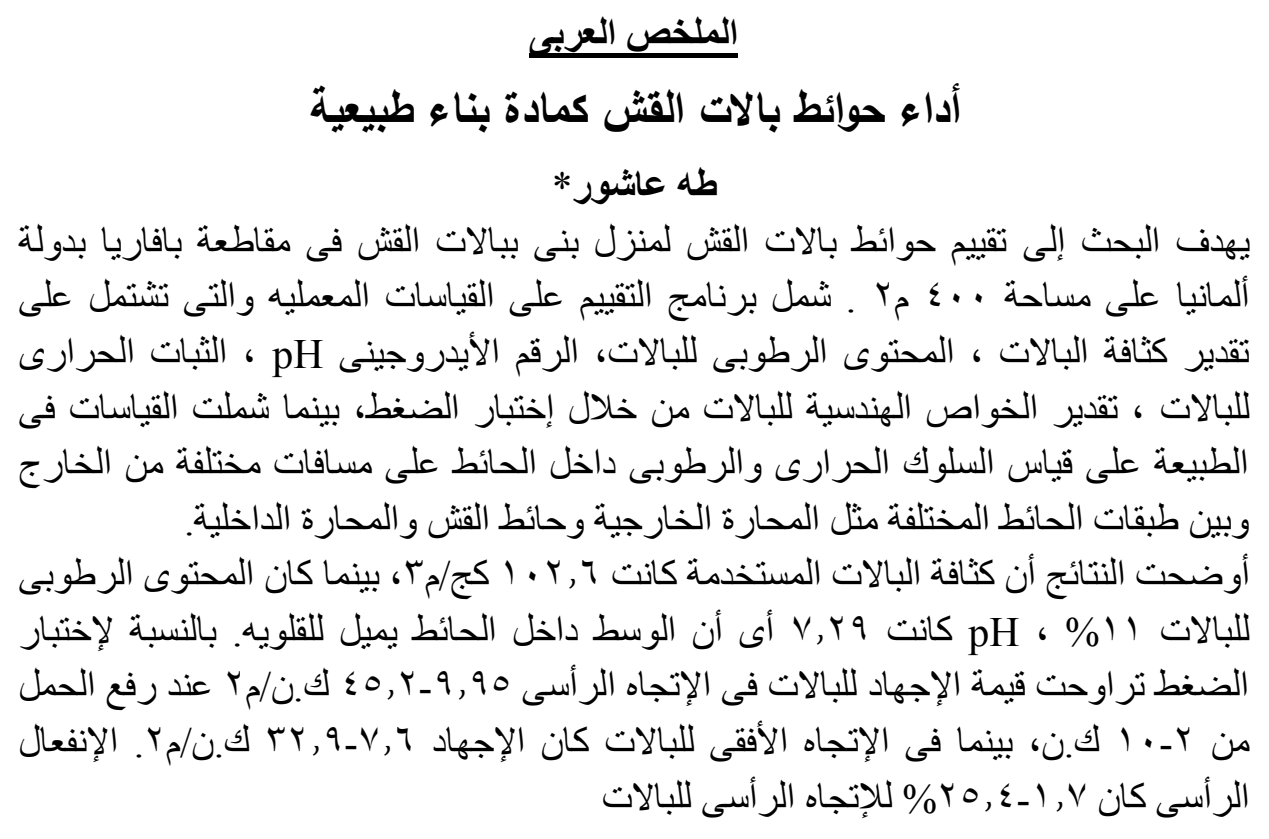

*مدرس الهندسة الزراعية - كلية الزر اعة بمشتهر - جامعة بنها - مصر. 


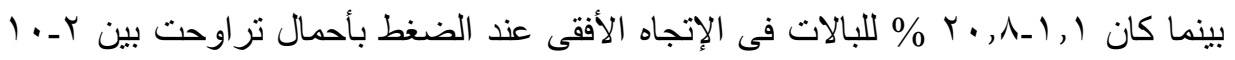

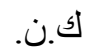
الإنفعال الأفقى للبالات فى الإتجاه الأفقى كان أعلى من الإتجاه الر أسى. يلاحظ أيضا أن الإنفعال

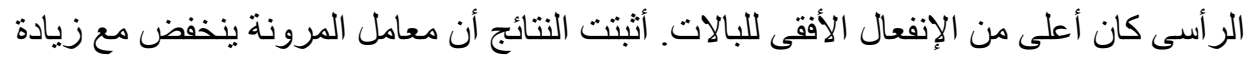

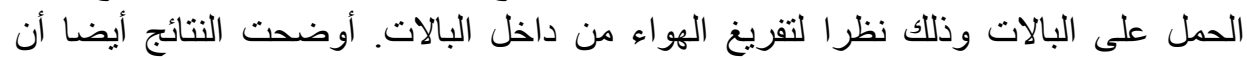

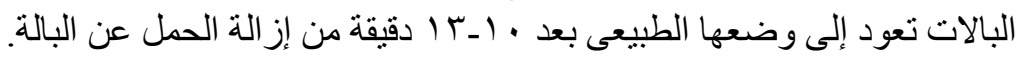

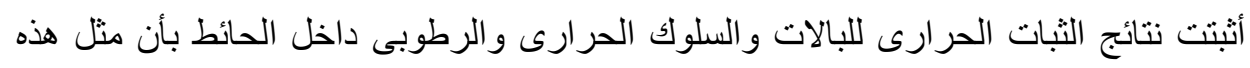

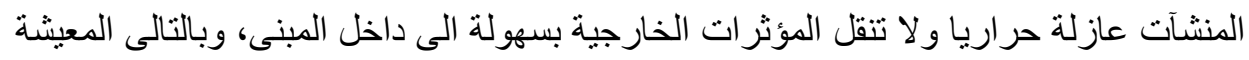

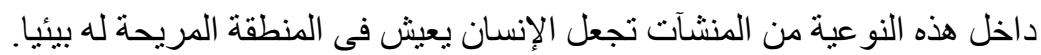

